\title{
Formulation of methods reducing landslide phenomena and the collapse of career slopes during open-pit mining
}

\author{
Abdrakhman Begalinov ${ }^{1}$, Vitalii Khomiakov $^{2}$, Yerdulla Serdaliyev ${ }^{1}$, Yerkin Iskakov $^{1, *}$, and \\ Aibar Zhanbolatov ${ }^{1}$ \\ ${ }^{1}$ Satbayev University, 50013, Almaty, Satbayev Str., 22, Kazakhstan \\ ${ }^{2}$ Kazakh Leading Academy of Architecture and Civil Engineering, 50050, Almaty, Ryskulbekov Str., \\ 28, Kazakhstan
}

\begin{abstract}
In this article, methods of reducing landslide phenomena and collapse of career of slopes, in the extraction of minerals with the open-pit mining approach are set out. The ways of uncovering upper argillaceous acclivities with the creation of buttresses made from rocky minerals are suggested. Also, technological frameworks of the establishment of acclivities of benches in primary resources, with preliminary conduct of the research on the deformation of the minerals from the drilling-andblasting activities are offered. On the basis of the dynamic processes of blasting and resistance of the massif to the breakage, there is a formula offered, for determining the rate of fracturing, and the methodology of calculation of the specific charge of the blasting substance, including and excluding the fracturing of the massif is substantiated. The technique of defining the parameters of buttresses, used in strengthening of the acclivities, piled with unstable argillaceous and friable minerals, is also suggested.
\end{abstract}

\section{Introduction}

Solving the problem of ensuring the sustainability of the acclivities of benches and edges of pits, is aimed at setting up economic and safe conditions for establishing mines with the open-pit approach.

Therefore, the research must be conducted on the basis of a thorough study of all factors, affecting the resilience of the acclivities of benches, taking into account the specific conditions of establishing the particular deposit.

Most of the open-pit mining quarries of Kazakhstan are entailed with deformations of the edges of massifs. Deformation processes represent continuous and consequential occasions, starting from their creation and ending with landslides and collapses. In any case, deformations of the acclivities of quarries decrease the main advantages of the openpit mining approach and cause significant material harm to the mining plant, violating the correct and safe conduct of excavating activities [1, 2, 3]. Therefore, the problem of

\footnotetext{
* Corresponding author: is.yerkin@gmail.com
} 
ensuring the sustainability of the acclivities of pits is one of the most important issues in mining.

The experience in mine refinement with the open-pit method shows that it is much easier and effective to prevent landslides and collapses, rather than fighting them. For this purpose, it is necessary to envisage a list of actions in technical projects, which ensures the safety of the edges of massifs. It is mandatory to consider the building of buttresses made from rocky minerals, during the uncovering of the upper argillaceous acclivities. As regards primary resources, it is required to formulate technological schemes of the acclivities of benches, with the research about the deformation of the minerals, happening because of the drilling-and-blasting activities, conducted in advance.

The purpose of the work is the creation of innovative methods of ensuring the stability of the slopes and ledges of quarries during open-pit mining, securing efficient and safe mining of minerals.

\section{Solution technique and results}

It is necessary to carry out a whole range of activities to determine the areas of deformation in the marginal massifs during the mass blasting in the quarries. The impact of industrial blasting on the deformability of the massif is examined by mine surveying stations, which are placed on the top of the platforms of benches in the form of special lines, before the explosion. This enables to carefully define the sedimentary deformations of the massif and fixate the areas of flaws.

The information gathered from surveying industrial blastings showed that the expenditure of simultaneously exploding explosives in the quarries of Akbakay field reaches a significant amount: from 2 to 10 tons, and in some cases of individual blastings, it exceeds 10 tons. The quantity of explosives in a single borehole amounts to $100-150 \mathrm{~kg}$ and higher. The specific expenditure of the explosives by pits accounts for $0.42-1.16 \mathrm{~kg} / \mathrm{m}^{3}$ in practice, although the planned amount was $0.60-0.80 \mathrm{~kg} / \mathrm{m}^{3}$.

The zones of flaws as a result of the mentioned surveillance amounted to 3-5 meters, while the residual deformation approximated 30-50 meters. Moreover, the areas of flaws are extremely dangerous from the point of sustainability of the acclivities, as the formation of fractures leads to a significant reduction of the natural durability of the edges of the massif (to 50-75\%). One of the main guarantees of the sustainability of the non-working acclivities is to eliminate the fracturing in the project field. According to the results of monitoring numerous industrial and experimental explosions under conditions of rocky and half rocky minerals, we have identified empirical dependence of the size of flaws $(l)$ on the specific expenditure $(q)$ and the amount of the explosives, located in 1 running meter distance of the quarry face $\left(q_{f}\right)$. These correlations enable us to determine optimal charges of the explosives when $l=0$.

An effective way to reduce the deformation of an array from an explosion is to use lateral tapes with an angle of $60-75^{\circ}$ and diagonal schemes of short-blasting, which reduce the width of the zone of residual deformations by 1.5-2.0 times when mining near-edge tapes and ejecting ledges. Simultaneous use of deviated wells makes it possible to reduce the size of overdrill by 1.5-2.0 times, which significantly reduces the destruction of the underlying layers.

The application of diagonal schemes of delay-action blasting and deviated wells does not require additional costs, in addition, it improves the quality of breaking and crushing rocks and can be recommended for continuous drilling and blasting operations.

When using the specific consumption of explosives in the calculations, it is necessary to take into account the so-called fracturing coefficient $\left(k_{m}\right)$ of rocks. 
In general, fractured rocks have significantly lower strength characteristics than monolithic ones, due to the disintegration of the massif by fractures. It is clear that the explosion of a fractured massif requires a lower consumption of explosives than monolithic. As regards industrial experiments, it was established that when blasting a fractured massif, only an insignificant part of the rock, close to the explosive charge in the well, is crushed regardless of the degree of fracturing, and the main part remote from the explosive charge is crushed into natural separate parts. Therefore, we can assume that the fracture coefficient is

$$
k_{m}=\frac{q_{m o n}}{q_{f r}},
$$

where $q_{m o n}, q_{f r}$ - specific expenditures of explosives for blasting monolithic and fractured massifs, $\mathrm{kg} / \mathrm{m}^{3}$.

Based on the dynamics of the blasting process and the resistance of the rock mass to separation, the fracture coefficient as the ratio of the forces for separation and crushing of monolithic and fractured masses is determined by our formula

$$
k_{m}=1+10^{-2} \cdot \frac{\sin \alpha}{\sin \psi} \cdot \frac{\sigma_{s h}}{d_{f} \cdot \gamma},
$$

where $\alpha$ - slope angle, degrees; $\psi$ - steeply dipping crack line angle, degrees; $\sigma_{s h}-$ temporary resistance on the rock mass to shear along an inclined crack, $\mathrm{MPa} ; d_{f}-$ average size of an elementary structural block in a fractured massif, $\mathrm{m} ; \gamma$ - rock density, $\mathrm{kg} / \mathrm{m}^{3}$.

Taking into account the fracturing of the massif during blasting allows reducing explosive consumption by $10-20 \%$ without impairing the quality of the explosion. At the same time, a decrease in the specific consumption of explosives by the fracture factor of the massif favorably affects a decrease in its deformation in the marginal part.

The calculated data on the optimal specific consumption of explosives for the main types of rocks of the Akbakay quarry, based on the fracture coefficient for various types of explosives, are given in the table 1 . In this case, the specific consumption of explosives $\left(q_{\text {mon }}\right)$ for blasting the array without taking into account its fracturing is determined by our formula

$$
q_{\text {mon }}=\frac{0.01445}{p}\left(\sigma_{t}+0.5 \sigma_{s h}+800 \gamma\right),
$$

where $\sigma_{t}-$ resistance of rock to tear, $\mathrm{MPa} ; \gamma-$ rock density, $\mathrm{kg} / \mathrm{m}^{3} ; \sigma_{s h}-$ rock resistance to shear on the bottom of the ledge, $\mathrm{MPa} ; p$ - specific pressure of explosion products, $\mathrm{MPa}$; 0,01445 - well charge density coefficient $\Delta=0.95$.

Thus, the explosive density, the well drilling coefficient and the well diameter equals $\gamma_{b b}=0.90 \mathrm{t} / \mathrm{m}^{3}, c=1.05, d=0.243 \mathrm{~m}$, respectively. For the calculation of $\sigma_{s h}$, the following formula is offered

$$
\sigma_{s h}=\gamma h \cdot \operatorname{tg} \rho+\varphi
$$

where $h$ - ledge height, m; $\rho$ and $\varphi$ - angle of internal friction and adhesion of rocks, defined as $\sigma_{t}$ and $\gamma$ by laboratory tests.

Thus, taking into account the fracturing (the intensity and orientation of the cracks) during the design of drilling and blasting operations and the contour strip allows mining with the least destruction of the contour mass. 
Table 1. Drilling and blasting parameters during ejection of ledges on the project circuit.

\begin{tabular}{|c|c|c|c|c|c|c|c|}
\hline № & $\begin{array}{c}\text { Well } \\
\text { assignment }^{*}\end{array}$ & $\begin{array}{c}\text { Well } \\
\text { angle } \alpha, \\
\text { degrees }\end{array}$ & $\begin{array}{c}\text { Well } \\
\text { length } l \text {, } \\
\text { m }\end{array}$ & $\begin{array}{l}\text { Overdrill } \\
c, \mathrm{~m}\end{array}$ & $\begin{array}{l}\text { The distance } \\
\text { between the } \\
\text { wells in } \\
\text { a row } a, \mathrm{~m}\end{array}$ & $\begin{array}{c}\text { The amount } \\
\text { of explosive } \\
\text { charge in the } \\
\text { well } Q, \mathrm{~kg}\end{array}$ & $\begin{array}{c}\text { Number of } \\
\text { dispersions, } \\
n\end{array}$ \\
\hline \multicolumn{7}{|c|}{$\begin{array}{l}\text { 1. Separate ejection of ledges when doubling them } \\
\text { a) Ejection of upper ledges }\end{array}$} & \\
\hline I & $\begin{array}{c}\text { Gap } \\
\text { formation }(\mathrm{C})\end{array}$ & 70 & 17 & 1 & $2 ; 2.5 ; 3$ & $25 ; 35 ; 45$ & $6 ; 9 ; 12$ \\
\hline II & $\begin{array}{l}\text { Ejection (C) } \\
\text { Crushing (L) }\end{array}$ & $\begin{array}{l}70 \\
90\end{array}$ & $\begin{array}{c}17 \\
17.5\end{array}$ & $\begin{array}{c}1 \\
2.5\end{array}$ & $\begin{array}{c}2 ; 2.5 ; 3 \\
6\end{array}$ & $\begin{array}{c}45 ; 60 ; 75 \\
360\end{array}$ & $\begin{array}{c}6 ; 8 ; 10 \\
2\end{array}$ \\
\hline III & \begin{tabular}{|c|} 
Ejection (L) \\
Crushing (L)
\end{tabular} & $\begin{array}{l}70 \\
70\end{array}$ & $\begin{array}{l}17.5 \\
18.0\end{array}$ & $\begin{array}{l}1.5 \\
2.0\end{array}$ & $\begin{array}{c}2 ; 2.5 ; 3 \\
6\end{array}$ & $\begin{array}{c}75 ; 95 ; 110 \\
320\end{array}$ & $\begin{array}{l}4 \\
4\end{array}$ \\
\hline IV & Ejection (L) & 60 & 20.0 & 2.5 & $2 ; 2.5 ; 3$ & $60 ; 70 ; 90$ & 4 \\
\hline $\mathrm{V}$ & $\begin{array}{l}\text { Ejection (L) } \\
\text { Ejection (L) } \\
\text { Crushing (L) }\end{array}$ & $\begin{array}{l}90 \\
90 \\
90\end{array}$ & $\begin{array}{c}5.0 \\
9.5 \\
17.5\end{array}$ & $\begin{array}{l}- \\
- \\
2.5\end{array}$ & $\begin{array}{l}3 \\
3 \\
6 \\
\end{array}$ & $\begin{array}{c}60 \\
120 \\
400\end{array}$ & $\begin{array}{l}1 \\
2 \\
2\end{array}$ \\
\hline VI & Crushing (L) & 90 & 17.5 & 2.5 & 3 & 220 & 4 \\
\hline \multicolumn{7}{|c|}{ b) Ejection of the lower ledge under one slope with the upper ledge } & \\
\hline VII & \begin{tabular}{|l} 
Ejection (L) \\
Ejection (L) \\
Ejection (L)
\end{tabular} & $\begin{array}{l}90 \\
90 \\
90 \\
\end{array}$ & $\begin{array}{c}5.0 \\
9.5 \\
17.5 \\
\end{array}$ & $\begin{array}{c}- \\
- \\
2.5\end{array}$ & $\begin{array}{l}3 \\
3 \\
6 \\
\end{array}$ & $\begin{array}{c}60 \\
120 \\
400 \\
\end{array}$ & $\begin{array}{l}1 \\
2 \\
2 \\
\end{array}$ \\
\hline \multicolumn{7}{|c|}{ 2. Jointing of ledges } & \\
\hline VIII & $\begin{array}{c}\text { Gap } \\
\text { formation }(\mathrm{C})\end{array}$ & 70 & 32 & - & $2 ; 2.5 ; 3$ & $50 ; 70 ; 90$ & $8 ; 10 ; 12$ \\
\hline IX & \begin{tabular}{|c|} 
Gap \\
formation (C) \\
Ejection (L)
\end{tabular} & $\begin{array}{l}70 \\
90\end{array}$ & $\begin{array}{c}32 \\
17.5\end{array}$ & 2.5 & $\begin{array}{c}2 ; 2.5 ; 3 \\
6\end{array}$ & $\begin{array}{c}50 ; 70 ; 90 \\
420\end{array}$ & $\begin{array}{c}7 ; 9 ; 12 \\
2\end{array}$ \\
\hline $\mathrm{X}$ & \begin{tabular}{|c|} 
Gap \\
formation (C) \\
Crushing (L) \\
Crushing (L)
\end{tabular} & $\begin{array}{l}70 \\
70 \\
90 \\
\end{array}$ & $\begin{array}{c}32 \\
18 \\
17.5 \\
\end{array}$ & $\begin{array}{c}- \\
2.0 \\
2.5\end{array}$ & $\begin{array}{c}2 ; 2.5 ; 3 \\
6 \\
6\end{array}$ & $\begin{array}{c}50 ; 70 ; 90 \\
140 \\
420\end{array}$ & $\begin{array}{c}7 ; 9 ; 12 \\
3 \\
3 \\
\end{array}$ \\
\hline
\end{tabular}

* The type of used explosive is indicated in brackets: $\mathrm{C}$ - cartridged; $\mathrm{L}$ - loose.

The most effective way of increasing the stability of stationary ledges is the contour blasting of charges. Two methods of blasting the charges of the contour series are practically used: before blasting the main charges of crushing in the near-edge strip (the method of preliminary slot formation); after breaking off the contour strip ("smooth" blasting).

Preliminary slot formation is a more efficient way of ejection of ledges. Contour charges with this method of blasting in an undisturbed massif, or in other words, before the approach of mining to the design circuit for the conditions of the Akbakay quarry, are located at a distance of at least $30-40 \mathrm{~m}$.

After the explosion of the contour charges in the array, a narrow gap is formed, which significantly reduces the explosive load from the main charges of crushing, eliminates the formation of punctures and almost completely eliminates the deformation of the contour array. Along the row of contour charges after mining the near-edge strip, an even stable slope wall with visible traces of wells is formed. 
It was established that the smaller the distance between the contour row wells, and accordingly the charge in the wells, the slope surface is evener. However, an increase in the cost of drilling-and-blasting activities at the same time negatively affects the economy of the enterprise. Therefore, in practice, either experimentally or theoretically it is necessary to determine the optimal distance between the contour wells in a row and the amount of charge in the wells to create a preliminary gap.

We have also found that the method of preliminary slit formation is most effective in rocky fractured massifs with the large block structure. The spatial orientation of the cracks has a significant impact on the effectiveness of the application of pre-slotting. The highest quality gap is obtained when the contour wells are parallel to the main system of fractures since the interaction of the charges of two wells most easily occurs with the opening of natural cracks.

"Smooth" blasting is used when the proximity of the blasting front to the design loop does not allow the creation of a preliminary gap. During "smooth" blasting, contour charges separate the most destructive layer from the escarpment surface of the ledge and form a more stable and even surface. It does not make sense to achieve high purity of the slope surface by this method of the ejection, with the approaching of the contour row wells, as the cracks and deformations existing behind the contour line of the explosion of the main crushing charges cannot be reduced by changing the parameters of the contour charges. Drilling of contour wells and blasting of contour charges can be carried out after blasting the main charges with a slowdown of $50-70 \mathrm{~m} / \mathrm{s}$.

The combination of preliminary slit formation and "smooth" blasting is used when doubling or tripling ledges and on the design contour. In this case, the wells drilled along the contour to the entire depth of the doubled ledges serve for creating a preliminary gap only on the lower ledge, and for the upper ledge, they are used as for "smooth" blasting, only if the last run has to be worked out on this ledge.

In the general case, the explosive charge per 1 running meter of a contour borehole for establishing a preliminary slit or for "smooth" blasting can be determined by our formula

$$
q_{r . m}=1.5 \cdot 10^{7} \cdot \frac{a^{2}}{v_{g}} \cdot\left(\frac{\sigma_{s t}}{Q_{b b}}\right)^{3 / 2},
$$

where $a$ - distance between the wells, $\mathrm{m} ; v_{g}$ - detonation speed, $\mathrm{m} / \mathrm{s} ; Q_{b b}$ - explosive density, $\mathrm{kg} / \mathrm{m}^{3} ; \sigma_{s t}$ - rock resistance to stretching, $\mathrm{MPa}$.

The dependence (5) is interpreted into the nomogram (Fig. 1), which makes it possible to quickly and accurately determine the explosive density $Q_{b b}=0.9 \mathrm{~g} / \mathrm{cm}^{3}$.

Ejection of the ledges with the help of contour blasting according to special technological schemes, makes it possible to increase the slope angle by $5-15^{\circ}$ in comparison with the slope angles obtained with conventional drilling and blasting technology, and it also ensures long-term stability of the ledges.

During the development of the Akbakay deposit, clay deposits with a thickness of up to $20 \mathrm{~m}$ were discovered on the design contours of the upper horizons (Fig. 2). Over time, as a result of feeding them with water (spring and flowing along the upland ditch), deformations arose in the form of mudflows, subsidence, and landslides. Therefore, the task of strengthening them has appeared.

In the practice of open-pit mining of mineral deposits, artificial methods of strengthening slopes are used, which are used as a method of preventing deformation of the instrument array, which allows reducing non-production costs of stripping. One of the ways of strengthening slopes, composed of clay and loose rocks, is the creation of buttresses from rocks, which act as a load, exerting a stabilizing effect on landslides. 


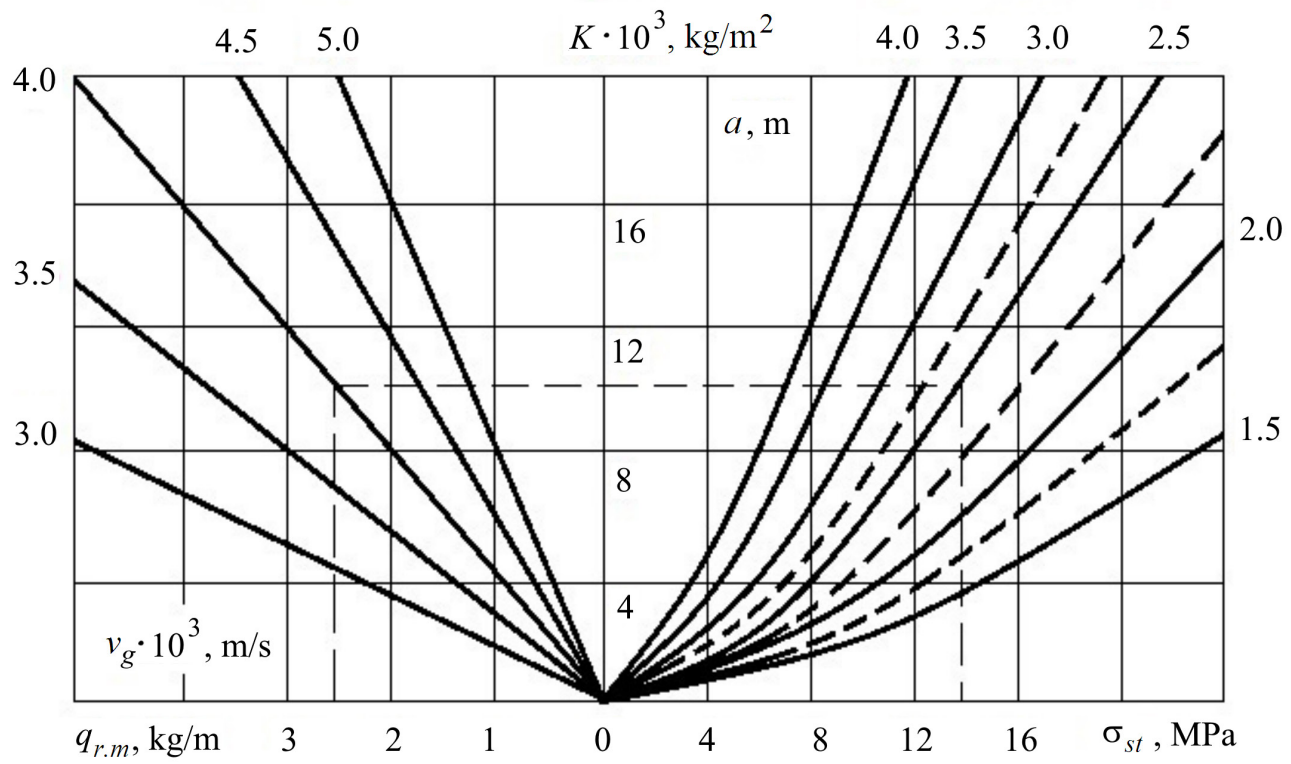

Fig. 1. Nomogram for determining explosive charge values per 1 r.m. of wells when creating a preliminary slit: $K$ - adhesion force along the contour, $\mathrm{kg} / \mathrm{m}^{2} ; a$ - distance between the wells, $\mathrm{m} ; v_{g}-$ detonation speed, $\mathrm{m} / \mathrm{s} ; q_{r . m}$ - the explosive charge per 1 running meter $\mathrm{kg} / \mathrm{m} ; \sigma_{s t}$ - rock resistance to stretching, MPa.

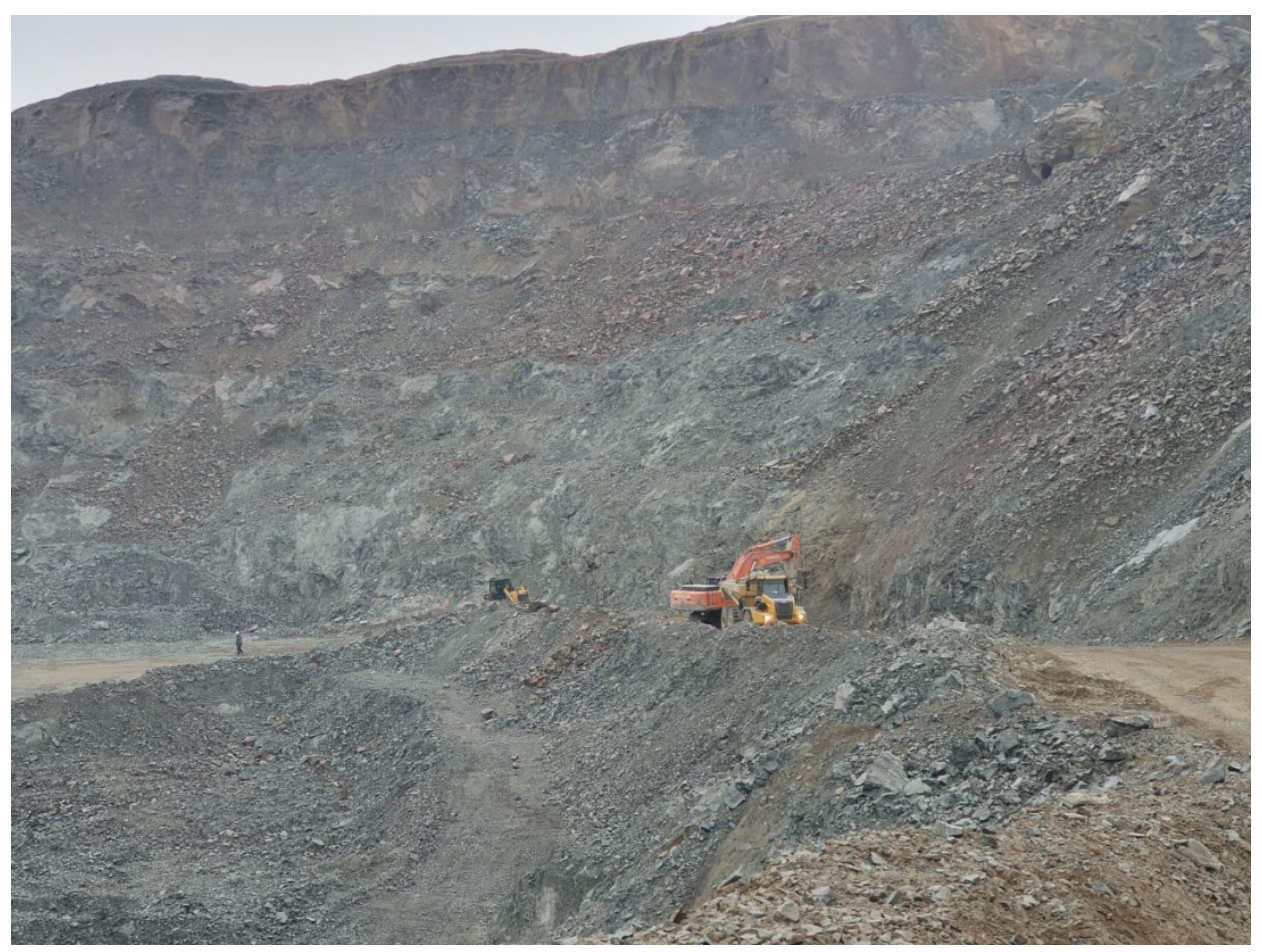

Fig. 2. Open-pit development of Akbakay field.

The construction of buttresses is preceded by an assessment of the stability of the clay slope and the calculation of the loading parameters of the rock [4]. The methodological 
approach to solving this problem is as follows. The reinforced slope is considered to consist of two parts - the upper unreinforced and the lower, which is the buttress. If it is advisable to form a buttress at its natural angle, you can put it on the design contour at any angle that does not exceed the temporarily stable angle. This allows varying the ratio of the heights of the buttress and unreinforced section, in compliance with the condition of equality of the stability coefficients of these parts of the slope, thereby introducing a certain universality when using the proposed methodology.

Taking the height of the buttress equal to half the height of the reinforced ledge, the width of its base at a given height is determined by the following method.

A sufficiently stable slope angle corresponding to $n=1$ is found to ensure safe operation during the construction of the buttress. Given the derivative values of the width of the buttress base, the stability of the slope is evaluated taking into account the influence of rock powder. The necessary width of the buttress base $\mathrm{d}_{w}$ is determined by our formula

$$
d_{w}=d_{0}\left[\left(n_{d}-n\right) /\left(n_{u}-n\right)\right],
$$

where $d_{0}$ - accepted starting value of the buttress base, $\mathrm{m} ; n_{d}$ - allowable stability coefficient of the reinforced slope; $n_{u}$ - slope stability coefficient, loaded with buttress with a base; $n$ - maximum coefficient of slope stability.

Further improvement by the methods is the use of the principle of equality of the stability coefficients of the upper, unstressed part of the slope and the entire ledge, taking into account the influence of buttress. Moreover, if the upper platform of the buttress is not used, the stability coefficient of the unreinforced part of the slope may be less than that required for the entire ledge as a whole, however, the width of the site should be sufficient to stabilize unstable rocks.

Using this principle, the optimal profile of the reinforced slope can be determined, based on specific conditions:

1. The high cost of excavation and transportation of weak rocks outside the quarry of the reinforced ledge, as well as the cost and technological restrictions from rock spillage, determine the minimum volumes and the created buttress to stabilize the site (Fig. 3, a).

2. The reduced distance of transportation of rock at the buttress compared with transportation to an external dump makes it profitable for the mining company to create an internal dump, which serves as a buttress of maximum volume (Fig. 3, b).

3. The required amount of occurrence of the fortified area (the distance between the lower edge of the buttress and the upper edge of the reinforced ledge) should be minimal (Fig. 3, c, d).

4. If the upper platform of the buttress is used for the construction of the transport road, then a variable ratio of the heights of the buttress and the unsecured part of the ledge is required.

The technique for determining the buttress parameters for the first case includes:

1) determination of temporarily stable slope of the reinforced area;

2) then the slope height for which $n=1.5$ is found, while maintaining the calculated angle in the first paragraph;

3) the buttress height as $h_{k}=h_{y}-h$ is calculated, where $h_{y}$ is the total height of the reinforced slope; $h$ is the height of the not strengthened part of the slope;

4) with the known height of the buttress and the stability coefficient of the reinforced slope as a whole $(n=1.5)$ the required height and width of the buttress are determined. For this, it is necessary to use correlation (6).

Then the specifics of the solution have to be done. The design contour of the reinforced slope and the designed buttress is built up on the profile and the values of the berm of the 
buttress formation site and the upper buttress platform are determined graphically. The measured values should not be less than technologically possible data.

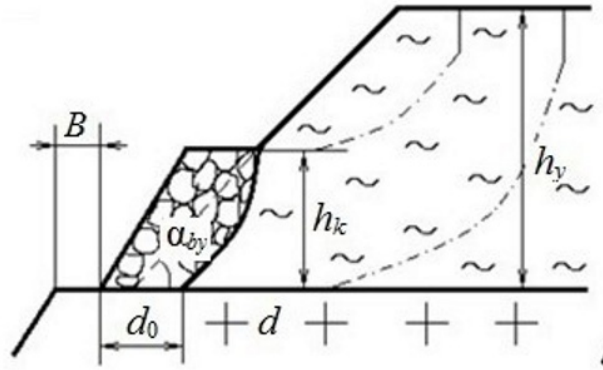

(a)

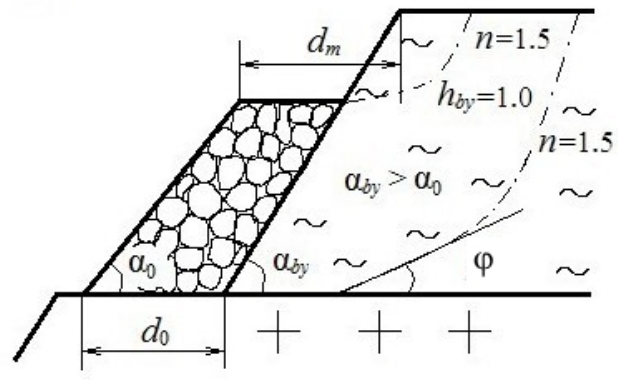

(c)

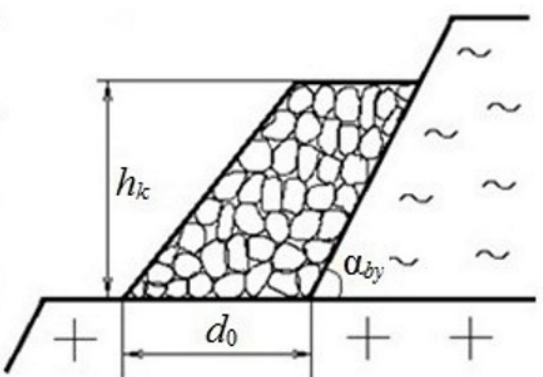

(b)

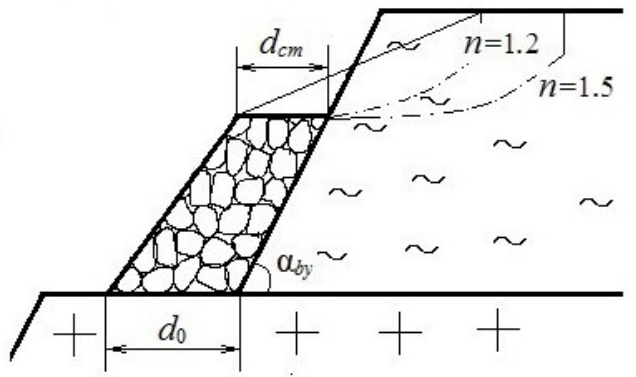

(d)

Fig. 3. Explanation of the buttress parameters: a, b - with a minimum amount of rock powder; $c, d-$ with a minimum planting in the plan; $B$ - width of the prism of possible collapse, $\mathrm{m} ; d_{0}$ - accepted starting value of the buttress base, $\mathrm{m} ; d$ - required calculated width of the buttress base, $\mathrm{m} ; h_{k}-$ buttress height, $\mathrm{m} ; h_{y}$ - ledge height, $\mathrm{m} ; \alpha_{b y}-$ temporarily stable ledge angle, degrees; $d_{m}$ - width of the upper buttress platform, $\mathrm{m} ; d_{c m}-$ minimum width of the upper platform for buttress creation, $\mathrm{m}$; $n$ - maximum coefficient of slope stability; $n_{b y}$ - coefficient of temporary stability; $\varphi$ - angle of internal friction, degrees; $\alpha_{0}$ - buttress angle, degrees.

In the case when it is advantageous to create an internal dump (Fig. 3), the technique for determining the buttress contains solutions to the problems:

1) determination of a temporarily stable angle for the amount of $h$;

2) adoption of the width of the upper platform, ensuring the normal operation of technological equipment;

3 ) finding the width of the lower buttress pad (graphically according to the mining plan or based on economic considerations);

4) determination of the maximum possible height of the buttress from the known values of the dimensions of the sites and the angle of natural acclivity of rock formations.

The solution is examined by checking the stability of the reinforced slope $(n>1.5)$ and assessing the bearing capacity of the rocks of the buttress base.

For the conditions of the Akbakay field, the stability of the underlying ledges was assessed, on which the rock was evaluated during the formation of the buttress, taking into account the additional load on the weight of the buttress.

If it is necessary to determine the buttress parameters (in the case of ensuring minimum planting), two possible solutions are available due to the ratio of the angles of the temporarily stable weak array and the angle of the internal friction $\alpha_{b y}, \alpha_{d y}, \alpha_{0}$. Under the condition $\alpha_{0}>\alpha_{d y}>\alpha_{b y}$, the method for determining the buttress parameters is identical to the previously considered one, the initial calculation parameter is $h_{k}=h$. 
If $\alpha_{b y}>\alpha_{0}>\alpha_{d y}$, then the calculation scheme is used (Fig. 3, c):

1) $\alpha_{b y}$ is determined for the height $h$;

2) by the method of successive approximation, minimization of the function is achieved

$$
F=h_{k} \operatorname{ctg} \alpha_{0}+d_{m}+\left(h-h_{k}\right) \operatorname{ctg} \alpha_{b y} .
$$

The calculation control is achieved by checking the sufficiency of the width of the upper buttress pad to stabilize the rocks of the upper unstressed part of the slope (Fig. 3, d).

When using the upper buttress platform for the device of the traffic road, the initial parameters for the calculation are the values of $h_{k}$ specified by the design exit angle, and $d_{\min }$ is the minimum width of the transport line. The remaining parameters are found from the condition that the stability coefficients of the upper part of the ledge are equal (provided that the rock mass is safe to transport) and the entire fortified site as a whole $n=1.5$. If at a given height $h_{k}$ the calculated width of the upper buttress pad is put into practice, conditions $n=1.5$ are achieved by flattening the slope of weak rocks.

The proposed methodology serves for the wider use of buttresses in the fight against landslide phenomena since it has a certain universality in determining the buttress parameters.

In the construction of buttresses, a special role must be given to the creation of their foundations, which should be deepened by $1.5-2.0 \mathrm{~m}$ into the underlying rocks. It is advisable to carry out strengthening works in the winter period.

According to the proposed method, buttresses were built at many quarries in Kazakhstan (Fig. 4). At the same time, an economic effect was achieved by reducing the volume of stripping operations and the transportation of rock. At the same time, an effect of economy was achieved by reducing the volume of stripping operations and the transportation of rock.

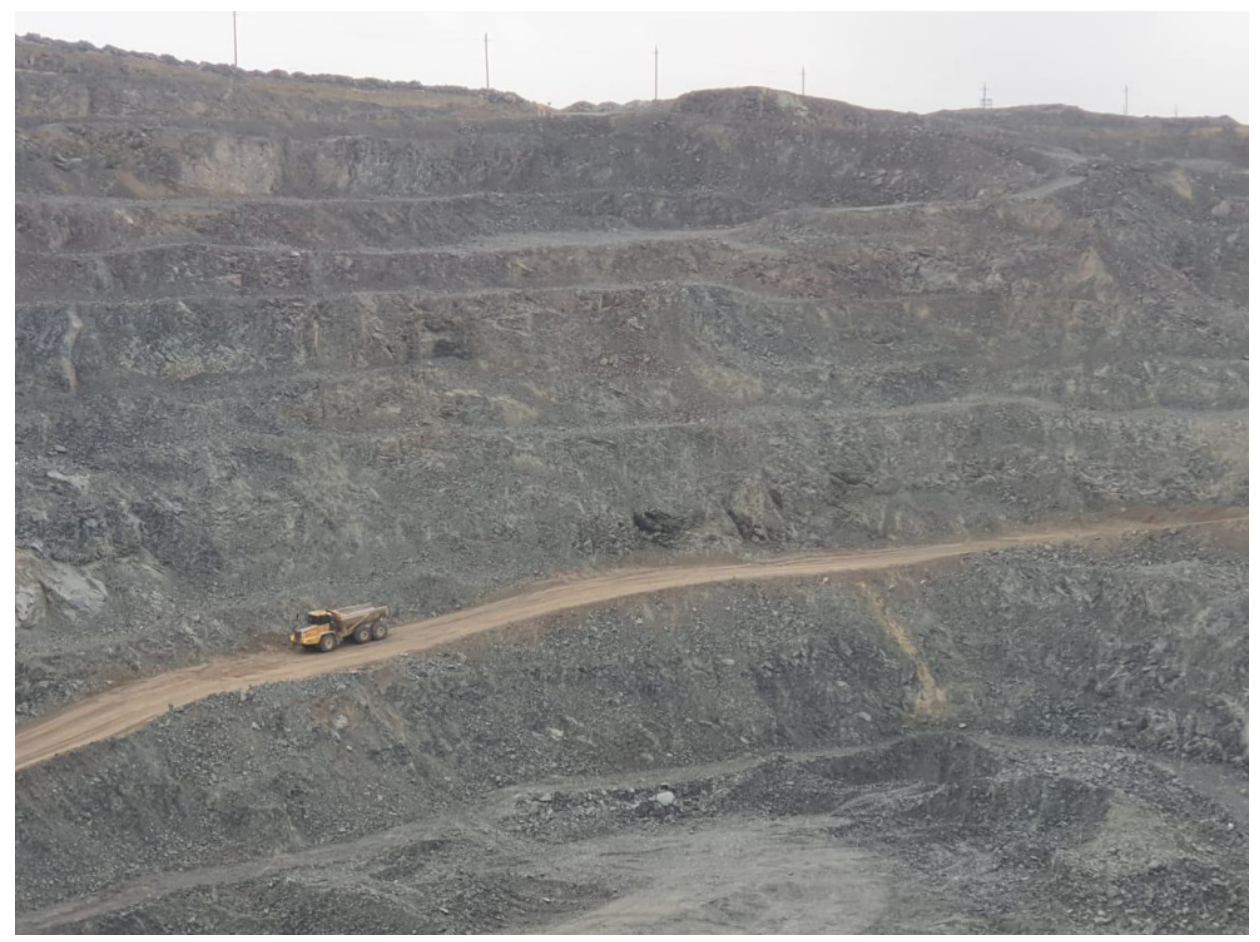

Fig. 4. Fortified clay slope buttress on the quarry of Akbakay field. 


\section{Conclusions}

The development of ways of reducing landslide phenomena and the collapse of career slopes in mining practice has allowed to reasonably increase the slope angles of ledges and edges of some quarries in Kazakhstan (Akbakay field), and to develop additional mineral reserves. As a result, a reduction in the volume of stripping operations was obtained by $22-28 \%$, the receiving capacity of dumps was increased, and land areas occupied by mining were reduced by $35 \%$. On top of that, by increasing the receiving capacity of dumps, reducing the volume of uncovering operations of transporting quarry edges, using buttresses to prevent landslide phenomena and establishing rational slopes, production costs can be reduced to $18-27 \%$.

\section{References}

1. Trubetskoi, K.N., Khronin, V.V., Krasnianskii, G.L. (2001). Proektirovanie karerov. Moskva: Izdatelstvo Akademii gornykh nauk, 1

2. Arsentev, A.I., Kholodniakov, G.A. (1994). Proektirovanie gornykh rabot pri otkrytoy razrabotke mestorozhdeniy. Moskva: Nedra

3. Galperin, A.M. (2003). Geomekhanika otkrytykh gornykh rabot. Moskva: Izdatelstvo Moskovskogo gosudarstvennogo gornogo universiteta

4. Nurpeisova, M.B., Kovrov, A.S. (2016). Upravlenie ustoichivostiu karernykh otkosov. Dnepr: Litograf 